\title{
Nitrogen accumulation and partitioning by winged bean in response to support systems
}

\begin{abstract}
An experiment was carried out to determine the partitioning and accumulation of nitrogen in plant components, nitrogenase activity and their relationships with seed yield of a local cultivar of winged bean (Psophocarpus tetragonolobus (L.) DC.) grown on three support systems of 0,1 , and $2 \mathbb{E m}$ height under field conditions. Total nitrogen accumulation and nitrogen partitioning were determined throughout the growing season by measuring nitrogen content and concentration in above-ground plant tissues (leaves, stems, petioles and pods). Support heights of 1 and $2 \mathbb{\mathrm { m }}$ significantly increased total nitrogen accumulation in component parts of the plant, nitrogenase activity, nodulation, total dry matter accumulation and seed yield compared with the control. Plants grown on supports accumulated significantly higher leaf nitrogen at the vegetative stages and the contribution of seed nitrogen was also significantly higher compared with unsupported plants. Nitrogenase activity increased with onset of flowering but declined during the pod formation stage in plants grown on a support system. Unsupported plants showed higher nitrogenase activity prior to flowering possibly due to lack of photosynthate and, consequently, early senescence of leaves.
\end{abstract}

Keyword: Nitrogen accumulation; Nitrogen partitioning; Winged bean; Support system 